\title{
The Impact of Mass Sports Work in Educational Institution on the Formation of Cadets'Value Attitude Towards Physical Education
}

\author{
Serhii Romanchuk', Evhen Anokhin'1, Iryna Tychyna², Viktor Dobrovolskii ${ }^{3}$, Roman Pidleteichuk', Serhiy \\ Homanyuk $^{5}$, Vitaliy Kirpenko ${ }^{5}$, Artur Oderov ${ }^{1}$ and Volodymyr Klymovych ${ }^{1}$
}

${ }^{1}$ National Academy of the Army, Department of Physical Education, Special Physical Training and Sports, Lviv, Ukraine, ${ }^{2}$ Ivan Franko Zhytomyr State University, postgraduate student of the Pedagogy Department, Zhytomyr, Ukraine, ${ }^{3}$ Military Institute of Taras Shevchenko National University if Kyiv, Military Training Department, Kyiv, Ukraine, ${ }^{4}$ National University of Ukraine on Physical Education and Sport, Physical Education Theory and Methods Department, Kyiv, Ukraine, ${ }^{5}$ Kharkiv National University of the Air Force named after Ivan Kozhedub, Department of Physical Education, Special Physical Training and Sports, Kharkiv, Ukraine

\begin{abstract}
Within the functioning of the physical education system of higher educational institutions, a four-year pedagogical experiment was carried out regarding cadets' value attitude formation to physical education activity. According to the results of the research, a significant improvement in the formation of the cadets' value attitude to physical education activity was recorded: in $93.6 \%$ of cases, the cadets of the experimental group identified a personally significant sport; $96.7 \%$ of cadets will continue to play their favourite sports after graduation; $90.0 \%$ of cadets recognized the importance of substantial and procedural aspects of physical education activity "for themselves" as a subject; $83.3 \%$ "for themselves" as a specialist, and $100 \%$ "for themselves" as an officer. The results of the practical implementation of the author's program confirmed the effectiveness of the proposed pedagogical influences. The results obtained indicate an increase in objective and subjective indicators of the formation of a value relationship, which affected the level of sports and physical fitness $(p<0.05)$. The presence of productive experience in sports activities, the formed value attitude of the majority of graduates involved in the author's program, suggests that they can continue to exhibit high physical activity during their professional activities, which will help to reduce the time for adaptation and maintain the level of professional performance.
\end{abstract}

Keywords: programme, cadet, value, attitude, sport

\section{Introduction}

For some decades, there have been significant changes in all spheres and branches of public life in Ukraine. Abandoning the administrative-command system, Ukrainian society strives for democracy. The new system requires the updating of forms, means, and methods of management; therefore, the necessity of considering a person in his mental and physical integrity is becoming more acute.

Until recently, the efforts of educational specialists and scholars in physical education were mainly focused on the develop- ment of physical qualities and motor skills, yet with insufficient attention to the "spiritual" aspect (values, motives, needs, interests, ambitions) of a particular personality. Under such circumstances, the efficiency of the physical education process of the younger generation has been significantly reduced. Moreover, the overwhelming majority of the population has not formed a positive value attitude to physical education and regular physical activity (Bolotin, Bakayev, \& Vazhenin, 2016; Klymovych, Olkhovyi, \& Romanchuk, 2016; Oderov et al., 2017).

These problems are inherent in military education sys-

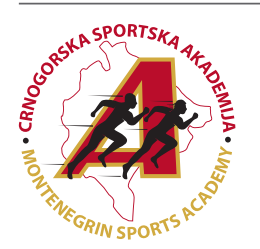

Correspondence:

S.V. Romanchuk

National Academy of the Army, Department of Physical Education, Special Physical Training and Sports, Heroyiv Maydanu, 79012 Lviv, Ukraine

E-mail:asv-fpis@ukr.net 
tems. The urgency of their resolution is derived from the low levels of physical preparedness and physical activity of the officers, and the inability of most officers to organize the process of self-improvement (Rolyuk et al., 2016). In this regard, one of the main prerequisites for achieving the goal of physical training in military educational institutions (the formation of a personal physical culture) is the advancing formation of cadets' motivational-value attitude to physical culture (Grankin \& Kuznecova, 2017; Kamaiev et al., 2018).

Various authors (e.g., Costa et al., 2016) acknowledge that during the period of study at a higher educational institution a cadet does not develop a sense of personal interest in regular physical exercises, which means the value attitude to these activities is not formed. In this regard, a number of works have recently identified a tendency to study the motivational aspects of the cadets' activities at higher educational institutions (e.g., Pichugin, Griban, \& Romanchuk, 2011) and, on this basis, to search for ways to optimize physical training in the interests of professional military activity have been started. However, an insignificant role in these studies is played by mass sports, which is currently reduced to the form of additional physical training classes, which, according to several authors (e.g., Prontenko et al., 2018) reduces the educational value of mass sport. Therefore, the determination of the possibilities for its use in forming a value-based attitude to physical education is relevant.

The purpose of the study is to determine the effectiveness of the program of formation of the value attitude of cadets to physical education activities and to confirm the feasibility of applying the proposed program and the need for further development of the problem associated with value-oriented activity.

\section{Methods}

To determine the effectiveness of the programme of the cadets' value attitude formation to physical education activities, we conducted a pedagogical experiment on the basis of the National Academy of the Army from 2016 to 2019. The experiment was conducted in hours of mass sports work, which are defined by the guidance document on physical training in the Armed Forces of Ukraine (one hour twice on weekdays and three hours on Sunday).

Two study groups took part in the experiment, which made up the control group $(\mathrm{CG}=30)$ and the experimental group $(E G=30)$. The cadets' lives were regulated by their daily routine. The cadets' initial levels of sports and physical fitness and physical development were reliably the same, which allows us to judge the clarity of the experiment $(\mathrm{p}>0.05)$.

The content of CG classes during the hours of mass sports mainly included exercises from the physical education curriculum at the first stage. Moreover, according to the objectively existing position of the prevalence of the normative approach, the emphasis in the activities of the unit commander was aimed at ensuring academic performance in discipline and at fulfilling subordinates of VSK norms and requirements.

Mass sports work in the EG was consistent with our programme. Its essence is to determine the stages of activity by the degree of regulation: Stage I (1-2 courses) is strictly regulated; Stage II (3rd and senior courses) is partially regulated. The model programme of the value attitude formation to physical education activities at the stages is presented in Table 1.

Table 1. A programme model of the cadets' value attitude formation to physical education activities

\begin{tabular}{|c|c|c|}
\hline \multirow{2}{*}{ Numbers } & \multicolumn{2}{|c|}{ Stages and Courses of Education } \\
\hline & I Stage (1st-2nd courses) & Il Stage (3rd course and senior) \\
\hline \multicolumn{3}{|l|}{ Objectives: } \\
\hline - tactical & $\begin{array}{l}\text { 1. Improving the level of physical preparedness. } \\
\text { 2. Mastering sports and physical exercises element } \\
\text { by element and in integrity. } \\
\text { 3. Creation the attitude to the importance of sports } \\
\text { for an officer, specialist and "for oneself". }\end{array}$ & $\begin{array}{l}\text { 1. Improving the development of physical } \\
\text { qualities and motor skills. } \\
\text { 2. Perfection in a chosen sport. } \\
\text { 3. Achieving the optimal level of sports } \\
\text { qualification. } \\
\text { 4. Mastering the skills of self-improvement. }\end{array}$ \\
\hline - strategical & $\begin{array}{l}\text { 1. Effective management of the comprehension of } \\
\text { sports and physical exercises. } \\
\text { 2. Ensuring the necessary emotional richness of classes. }\end{array}$ & $\begin{array}{l}\text { 1. The provision of practical assistance in self- } \\
\text { improvement. }\end{array}$ \\
\hline $\begin{array}{l}\text { Sports and physical } \\
\text { exercises }\end{array}$ & $\begin{array}{l}\text { 1. The prevalence of sports } \\
\text { and physical exercises characterized by the } \\
\text { categories "general" and "special". }\end{array}$ & $\begin{array}{l}\text { 1. The prevalence of sports and physical } \\
\text { exercises, characterized by the categories of } \\
\text { "single" and "special." }\end{array}$ \\
\hline $\begin{array}{l}\text { Leading mass sports } \\
\text { activities }\end{array}$ & $\begin{array}{l}\text { 1. Cognitive } \\
\text { 2. Pre-educational }\end{array}$ & 1. Value-oriented \\
\hline $\begin{array}{l}\text { Characteristic of pedagogical } \\
\text { interactions }\end{array}$ & $\begin{array}{l}\text { 1. Predominantly subject-objective. } \\
\text { 2. Communication. }\end{array}$ & $\begin{array}{l}\text { 1. Predominantly subject-subjective. } \\
\text { 2. Interaction. }\end{array}$ \\
\hline $\begin{array}{l}\text { Specific features of participation } \\
\text { in the process of managing the } \\
\text { value attitude formation }\end{array}$ & $\begin{array}{l}\text { Scheme benefits } \\
\text { "Teacher - commander - cadet" }\end{array}$ & $\begin{array}{c}\text { Scheme benefits } \\
\text { "Teacher - cadet" (in "special" and "single" } \\
\text { sports) and "commander - cadet" (in "general" } \\
\text { sports) }\end{array}$ \\
\hline $\begin{array}{l}\text { System of competitions } \\
\text { characteristic }\end{array}$ & $\begin{array}{l}\text { 1. According to simplified rules. } \\
\text { 2. The predominant level of mass competitions: } \\
\text { "platoon - company - battalion" (and their equals). } \\
\text { 3. Selectively: "higher educational institution and } \\
\text { external competitions" }\end{array}$ & $\begin{array}{l}\text { 1. Preferred level: "faculty - higher educational } \\
\text { institution - external competitions." }\end{array}$ \\
\hline $\begin{array}{l}\text { Physical } \\
\text { training interconnection }\end{array}$ & Direct & Indirect \\
\hline
\end{tabular}


At the second stage, in accordance with the existing situation, the content and conduct of classes on mass sports work in the CG did not differ significantly from the first stage.

A specific feature of the organization and conduct of mass sports work in EG at the second stage was the freedom in choosing kinds of sports or physical exercises for further improvement and freedom in choosing activity forms (in sections or independently). The participation in competitions involving all the personnel ("general" sports and physical exercises) was obligatory.

A direct indicator of the value attitude formation was the results of a questionnaire among cadets about the need of physical activity "for themselves" as a subject, "for themselves" as a specific specialist in professional activity, "for themselves" as a future officer ("single", "special", "general"), as well as the severity of procedural motives and the inten- tion to engage in a selected sports after graduation. We developed the questionnaire, and it was evaluated by 45 experts ( $\mathrm{W}=0.859)$.

The result of the transformative type of mass sports activity was the indicators of cadets' sports qualifications, which were determined by analysing the competition protocols and physical fitness checklists, as well as indicators of cadets' physical fitness according to the results of physical exercises based on the conditions of the Physical Training Manual in the Armed Forces of Ukraine. To increase the reliability of the results obtained, the results of final exams and state exams were used (Olkhovyi, 2015).

\section{Results}

Based on the experiment result, the general positive dynamics of cadets' sports preparedness was revealed, both in the controlled and experimental groups (Table 2).

Table 2. Comparative characteristic of the experimental $(E G=30)$ and controlled $(C G=30)$ groups on the dynamics of sports qualification (\%)

\begin{tabular}{cccccccc}
\hline \multirow{2}{*}{ Groups } & Research Stage & $\begin{array}{c}\text { Candidate for } \\
\text { Master of Sport }\end{array}$ & I grade (\%) & II grade (\%) & III grade (\%) & $\begin{array}{c}\text { Overall } \\
\text { (\%) }\end{array}$ \\
\hline \multirow{2}{*}{ EG } & Initial Level & - & 10.0 & 10.0 & 6.7 & 16.7 \\
& After the 1st Stage & - & 10.0 & 30.0 & 20.0 & 60.0 & 100 \\
\hline & After the 2nd Stage & 10.0 & 30.0 & 40.0 & 20.0 & 10.0 & 20.0 \\
\multirow{2}{*}{ CG } & Initial Level & - & 3.3 & 6.7 & 13.3 & 26.7 & 43.3 \\
& After the 1st Stage & - & 3.3 & 16.7 & 33.3 & 56.7 \\
\hline
\end{tabular}

After the first stage in the experimental group, the general level of sports qualification is significantly higher than in the controlled group $(\mathrm{p}<0.05)$.

The data characterizing the level of CG cadets' sports qualification at the end of the second stage are congruent to some extent with the general state of mass sports work with traditional approaches to its organization and conduct (a low level of higher grades (10.0\%) and the predominance of the third grade $(33.3 \%$ among other grades). Also, due to the ratio of the dynamics of sports readiness of a particular CG cadet, it was revealed that at the second stage some members of this group had a decrease in qualifications by the end of the training period. A similar study in the EG showed that the level of cadets' athletic preparedness mainly increased or remained the same; no decline was observed.

For a more complete description, we conducted an analysis of the amount of conducted sports grades by a particular cadet of the experimental and controlled groups.

Table 3. Comparative characteristic of sport grades number in experimental and controlled groups (\%)

\begin{tabular}{ccccc}
\hline Groups & \multicolumn{4}{c}{ Number of sport grades (\%) } \\
& one & two & three & four \\
\hline EG & 20.0 & 53.3 & 20.0. & 6.7 \\
CG & 76.4 & 17.7 & 5.9 & - \\
\hline
\end{tabular}

As the data in Table 3 show, in the EG, $80.0 \%$ fulfilled the grades in two or more sports (physical exercises), while in the controlled group, this indicator is equal to $23.6 \%$ of the cadets' who fulfilled sports grades.

Another defining aspect of the differences between the cadets of the CG and the EG and the advantages of the developed and tested programme, accordingly, is the indicators of sports specialization (Table 4).
Sports grades in the CG were mainly fulfilled according to exercises directly related to the physical training programme (category "general"). In the experimental group, along with the same exercises, cadets achieved quite good results in other sports as well. At the same time, "general" sports also prevailed in the EG at the first stage, although cadets completing the second stage confirmed and increased the grade levels of the same types and exercises and were able to master the grade standards for other sports. 
Table 4. Characteristic of sports specialization in the experimental $(n=30)$ and controlled $(n=30)$ groups

\begin{tabular}{ccccc}
\hline Numbers & $\begin{array}{c}\text { CG } \\
\text { After the } \\
\text { I Stage (\%) }\end{array}$ & $\begin{array}{c}\text { After the II } \\
\text { Stage (\%) }\end{array}$ & $\begin{array}{c}\text { EG } \\
\text { After the } \\
\text { I Stage (\%) }\end{array}$ & $\begin{array}{c}\text { After the } \\
\text { II Stage (\%) }\end{array}$ \\
\hline Obtained Sports Qualification & 43.3 & 56.7 & 60.0 & 100 \\
Orienteering & - & 3.3 & - & 40.0 \\
Skiing & - & 3.3 & 10.0 & 40.0 \\
3 km Race & 16.7 & 30.0 & 30.0 & 66.7 \\
100 m Race & 6.7 & 10.0 & 10.0 & 10.0 \\
Overcoming Obstacles & 10.0 & 10.0 & 16.7 & 20.0 \\
Combat Sport & 3.3 & 6.7 & 6.7 & 6.7 \\
Weight-lifting & 3.3 & - & - & 10.0 \\
Officers'Triathlon & - & - & 3.3 & 3.3 \\
Sport Games & 3.3 & 3.3 & 3.3 & 3.3 \\
\hline
\end{tabular}

In our opinion, the participation of the CG and the EG cadets in the training process of combined teams is considered to be another indicator of the tested programme effec- tiveness in terms of increasing the level of sports preparedness by applying a personality-oriented approach. The results are presented in Table 5.

Table 5. Number of the experimental $(n=30)$ and controlled $(n=30)$ groups cadets participating in sports sections and higher educational institution combined teams

\begin{tabular}{|c|c|c|c|c|c|c|c|}
\hline \multirow{2}{*}{\multicolumn{2}{|c|}{ Groups }} & \multicolumn{5}{|c|}{ Types of Sport } & \multirow{3}{*}{$\begin{array}{c}\text { Overall } \\
10.0\end{array}$} \\
\hline & & \multirow{2}{*}{$\begin{array}{c}\text { Sport Games } \\
3.3\end{array}$} & \multirow{2}{*}{$\begin{array}{c}\text { Combat Sport } \\
3.3\end{array}$} & \multirow{2}{*}{$\begin{array}{c}\text { Orienteering } \\
-\end{array}$} & \multirow{2}{*}{$\begin{array}{c}\text { Athletics } \\
3.3\end{array}$} & \multirow{2}{*}{$\begin{array}{c}\text { Power } \\
-\end{array}$} & \\
\hline & CG & & & & & & \\
\hline Trage. & EG & 6.7 & - & - & 3.3 & - & 10.0 \\
\hline \multirow{2}{*}{ II Stage: } & CG & 3.3 & 6.7 & 3.3 & 3.3 & 3.3 & 20.0 \\
\hline & EG & 10.0 & 10.0 & 40.0 & 10 & 10.0 & 80.0 \\
\hline
\end{tabular}

Before moving to the subjective characteristics of the tested programme effectiveness, it is necessary to mention that during the questioning of cadets the basic requirements for carrying out such procedures were strictly provided and observed in order to clarify the value attitude.

\section{Discussion}

While defining a favourite sport, attention is drawn to the differently expressed uncertainties in the answers to this question by the CG and the EG cadets. Only two respondents among the EG cadets had difficulty with this question, whereas more than half did in the CG (53.3\%). The remaining part of the CG cadets named different kinds of sport games. This indicates that mainly the emotional form of the value attitude prevails (in this sense, sport games are self-sufficient) without the necessary value reflection among the CG cadets. Some cadets also added some types of martial arts, general physical training (as a kind of complex sport), and weight-lifting exercises.

The vast majority of the EG cadets define two and more types of sport for themselves. At the same time, the emotional aspect (sports games) and the semantic aspects of the value attitude are combined, highlighting the "special" sport and its component (running).

However, the definition of a favourite sport does not yet sufficiently characterize the value attitude to physical education activities. Therefore, the interest of our research was the question: "Will you be engaged in a selected sport (physical exercises) in future?"

According to the data in the tables, there is an insignificant degree of confidence in the CG that the person will be engaged in physical education activities, regardless of the conditions of professional activity, domestic and other conditions, and 20\% of the cadets of this group responded clearly negatively. In this regard, a considerably different point of view of the EG cadets, in which opinions about the necessity and value of physical education and the possibility of doing sports in future prevail.

However, it should be noted that the cadets involved in a "special" sport activity, orienteering, were aware that cultivating this sport in professional activities is highly dependent on external conditions; therefore $70 \%$ of them chose the second option in their answers. Thus, it must be recognized that this sport is more important and valuable for a cadet as a subject of the educational process. However, at the same time, an additional survey showed that even if there are no conditions for orienteering, cross-country running and acquired orienteering skills are valuable for them as components of orienteering.

Therefore, the substantive aspect, along with the procedural and resultant aspects of mass sports activities carried out according to the programme proposed, influenced the determination of the subjective significance of physical education activities.

As can be seen in the first stage, there are differences in the subjective characteristics of the controlled and experimental groups in relation to the substantive and procedural aspects of mass sports activities. At the same time, the positive attitude of cadets in both groups does not have significant differences in personal motives, in professional and duty motivations, which is probably objectively inherent in the first stage.

However, at the second stage, significant differences were revealed in the subjective significance of the substantive and procedural aspects of physical culture activity. In the EG, the indicators for "general", "special", and "single" increased (or 
remained at the same level), whereas in the CG the same indicators decreased, according to the table, especially in terms of personal and professional significance. Furthermore, an additional survey showed that the need for physical activity "for oneself" as an officer in $73.3 \%$ of cases is connected with the duty motivations, the need to participate in final tests.

It should also be mentioned that the overwhelming number of EG cadets in the formation of a value-based attitude to physical education activities confirm the positive role of the teacher of the physical training and sports department and the unit commander $(86.7 \%$ and $56.7 \%$, respectively), while the CG cadets responded positively in $20 \%$ and $33.3 \%$, respectively. These facts confirm our belief in the need for participation in mass sports activities, especially in terms of educational influences.

Thus, the objective indicators of sports preparedness and subjectively expressed indicators of the value attitude to physical education activities identified in the controlled and experimental groups indicate the effectiveness of the proposed programme for the formation of value attitude.
Higher indicators of the EG cadets in comparison with the CG were revealed even in the level of physical preparedness.

Also, due to the experiment results, the level of physical fitness increased in both controlled and experimental groups. The results are presented in Table 6 .

It should be noted that the overall assessment of physical fitness at the initial level has such a low score due to the fact of the transition of subjects from an "entrant" to a "cadet" category. Therefore, the reason for the decline in results was new living conditions, changes in the form of clothing, changes in regulatory requirements according to the NFP, etc.

The data obtained indicate marked changes compared with the initial level in almost all indicators. However, if we compare them not with their basic level but with each other, then higher progress is noted after the first stage in the EG in the development of endurance quality $(\mathrm{p}<0.05)$. Moreover, differences in the development of this quality become statistically significant after the second stage. Such a correlation with the same level of significance takes place in the integral assessment of physical fitness $(\mathrm{p}<0.05)$.

Table 6. The results of the cadets' physical fitness level of experimental and controlled groups before and after the experiment

\begin{tabular}{|c|c|c|c|c|c|}
\hline Numbers & Groups & Initial numbers & $\begin{array}{l}\text { After the 1st } \\
\text { Stage }\end{array}$ & $\begin{array}{l}\text { At the end of the } \\
\text { Experiment }\end{array}$ & $\mathbf{p}$ \\
\hline \multirow{2}{*}{ Pull-ups (number) } & EG & $11.4 \pm 0.8$ & $14.5 \pm 0.4$ & $15.2 \pm 0.5$ & \multirow{2}{*}{-} \\
\hline & CG & $11.8 \pm 0.6$ & $14.3 \pm 0.5$ & $15.0 \pm 0.4$ & \\
\hline \multirow{2}{*}{100 m Race (c) } & EG & $15.4 \pm 0.6$ & $14.5 \pm 0.5$ & $13.9 \pm 0.4$ & \multirow{2}{*}{-} \\
\hline & CG & $15.2 \pm 0.7$ & $14.6 \pm 0.6$ & $14.14 \pm 0.3$ & \\
\hline \multirow{2}{*}{ Dexterity Complex Exercise (c) } & EG & $10.1 \pm 0.5$ & $9.4 \pm 0.4$ & $9.38 \pm 0.4$ & \\
\hline & CG & $10.6 \pm 0.5$ & $9.57 \pm 0.4$ & $9.56 \pm 0.3$ & \\
\hline \multirow{2}{*}{3 km Race (min., c) } & EG & $13.34 \pm 0.15$ & $12.34 \pm 0.3$ & $12.16 \pm 0.4$ & \multirow{2}{*}{0.05} \\
\hline & CG & $13.39 \pm 0.3$ & $12.48 \pm 0.2$ & $12.41 \pm 0.2$ & \\
\hline \multirow{2}{*}{ Overall mark (average score) } & EG & $2.93 \pm 0.3$ & $4.4 \pm 0.4$ & $4.46 \pm 0.16$ & \multirow{2}{*}{0.05} \\
\hline & CG & $2.84 \pm 0.2$ & $4.34 \pm 0.3$ & $4.16 \pm 0.2$ & \\
\hline
\end{tabular}

The results obtained and the application of the principles of philosophy, pedagogy, pedagogical psychology, and cultural science made it possible to determine the conditions and substantiate the programme for the cadets' value attitude formation to physical education in the process of mass sports work.

The results of the practical implementation of the author's programme confirmed the effectiveness of the proposed pedagogical influences. The results obtained indicate an increase in objective and subjective indicators of the value attitude formation, which affected the level of sports and physical fitness $(\mathrm{p}<0.05)$.

\section{Acknowledgements}

There are no acknowledgements.

\section{Conflict of Interest}

The authors declare that there is no conflict of interest.

Received: 29 September 2019 | Accepted: 22 November 2019| Published: 01 February 2020

\section{References}

Bolotin, A., Bakayev, V., \& Vazhenin, S. (2016). Pedagogical model for developing skills required by cadets of higher education institutions of the Aerospace Forces to organize their kettlebell self-training Journal of Physical Education and Sport, 16(1), 177-186. doi:10.7752/
The productive experience in mass sports work and the formed value attitude of the majority of graduates involved in the author's programme suggest that they can express prolonged high physical activity during their occupation, which will help to reduce the time for adaptation and maintain the level of professional performance.

The results of our research confirm the feasibility of using the proposed programme and confirm the need for further development of the problem associated with the value-oriented type of activity.

jpes.2016.01028

Costa, A.M., Gil, M.H., Sousa, A.C., Ensinas, V., Espada, M.C., \& Pereira, A. (2016). Effects of concurrent strength and endurance training sequence order on physical fitness performance in adolescent students. Journal of Physical Education and Sport, 16(4), 1202-1206. doi:10.7752/ jpes.2016.04191

Grankin, N.A., \& Kuznecova, Z.M. (2017). Indices of functional state and reserve opportunities of cadets. Pedagogical-psychological and medicobiological problems of physical culture and sports, 12(1), 37-46. doi 10.14526/03_2017_232

Kamaiev, O.I., Hunchenko, V.A., Mulyk, K.V., Hradusov, V.A., Homanyuk, S.V., Mishyn, M.V., Martynenko, O.M., \& Shuryaev, V.P. (2018). Optimization of special physical training of cadets in the specialty «Arms and Military Equipment» on performing professional military-technical standards. 
Journal of Physical Education and Sport, 18(Supplement issue 4), 1808 1810. doi:10.7752/jpes.2018.s4264

Klymovych, V., Olkhovyi, O., \& Romanchuk, S. (2016). Adoption of youth`s bodies to educational conditions in higher educational institutions. Journal of Physical Education and Sport, 3(1), 620-622.

Oderov, A., Romanchuk, S., Fedak, S., Kuznetsov, M., Petruk, A., DunetsLesko, A., Lesko, O., \& Olkhovy, O. (2017). Innovative approaches for evaluating physical fitness of servicemen in the system of professional training. Journal of Physical Education and Sport, 17 (Supplement issue 1), 23-27. doi:10.7752/jpes.2017.s1004

Olkhovyi, O.M. (2015). Theory and methodology of scientific research in physical education and sport. KSAPC, 1(2), 143.

Pichugin, M.F., Griban, G.P., \& Romanchuk, V.M. (2011). Physical education of military servicemen: ZMINAU.

Prontenko, K., Griban, G., Prontenko, V., Andreychuk, V., Tkachenko, P.,
Kostyuk, Y., \& Zhukovskyi, Y. et al. (2017). Kettlebell lifting as a means of physical training cadets in higher military educational institution. Journal of Physical Education and Sport, 17(4), 2685-2689. doi:10.7752/ jpes.2017.04310

Prontenko, K., Griban, G., Prontenko, V., Opanasiuk, F., Tkachenko, P., Zhukovskyi, Y., \& Kostyuk, Y. (2018). Health improvement of cadets from higher military educational institutions during kettlebell lifting activities. Journal of Physical Education and Sport, 18(1), 298-303. doi:10.7752/jpes.2018.01040

Rolyuk, A., Romanchuk, S., Romanchuk, V., Boyarchuk, A., Kyrpenko, V., Afonin, V., \& Orest, L. (2016). Research on the organism response of reconnaissance officers on the specific load of military exercises. Journal of Physical Education and Sport, 16(1), 132-135. doi:10.7752/ jpes.2016.01022 